\title{
Bidirectional Modulation of Cocaine Expectancy by Phasic Glutamate Fluctuations in the Nucleus Accumbens
}

\author{
Nobuyoshi Suto, ${ }^{1,2,3}$ Greg I. Elmer, ${ }^{2}$ Bin Wang, ${ }^{1}$ Zhi-Bing You, ${ }^{1}$ and Roy A. Wise ${ }^{1}$ \\ ${ }^{1}$ Behavioral Neuroscience Branch, Intramural Research Program, National Institute on Drug Abuse, National Institutes of Health/Department of Health and \\ Human Services, Bethesda, Maryland 20892, 2 Maryland Psychiatric Research Center, Department of Psychiatry, University of Maryland School of Medicine, \\ Baltimore, Maryland 21201, and ${ }^{3}$ Department of Molecular and Cellular Neuroscience, The Scripps Research Institute, La Jolla, California 92037
}

While glutamate in the nucleus accumbens (NAS) contributes to the promotion of drug-seeking by drug-predictive cues, it also appears to play a role in the inhibition of drug-seeking following extinction procedures. Thus we measured extracellular fluctuations of NAS glutamate in response to discriminative stimuli that signaled either cocaine availability or cocaine omission. We trained rats to selfadminister intravenous cocaine and then to recognize discriminative odor cues that predicted either sessions where cocaine was available or alternating sessions where it was not (saline substituted for cocaine). Whereas responding in cocaine availability sessions remained stable, responding in cocaine omission sessions progressively declined to chance levels. We then determined the effects of each odor cue on extracellular glutamate in the core and shell subregions of NAS preceding and accompanying lever pressing under an extinction condition. Glutamate levels were elevated in both core and shell by the availability odor and depressed in the core but not the shell by the omission odor. Infusion of kynurenic acid (an antagonist for ionotropic glutamate receptors) into core but not shell suppressed responding associated with the availability odor, but had no effect on the suppression associated with the omission odor. Thus cocaine-predictive cues appear to promote cocaine seeking in part by elevating glutamatergic neurotransmission in the core of NAS, whereas cocaineomission cues appear to suppress cocaine seeking in part by depressing glutamatergic receptor activation in the same region.

\section{Introduction}

Environmental stimuli that predict drug availability become subsequent sources of drug craving (Childress et al., 1988; Ehrman et al., 1992) and relapse (Kosten et al., 2006) in humans and drug reinstatement in laboratory animals (Meil and See, 1996; Weiss et al., 2000). In animals trained to self-administer cocaine or heroin, response-contingent presentations of drug availability cues cause release of the neurotransmitter glutamate in the ventral tegmental area (VTA; You et al., 2007; Wise et al., 2008; Wang et al., 2012) and in the nucleus accumbens (NAS) (LaLumiere and Kalivas, 2008; Suto et al., 2010; see also Hotsenpiller et al., 2001); glutamatergic input to each of these brain regions can cause renewal of responding after apparent extinction of the response tendency (Cornish et al., 1999; Suto et al., 2004; Wang et al., 2005, 2012).

The ability of drug availability stimuli to promote drug seeking has been studied in some detail, but the role of stimuli that predict unavailability or omission of drugs has received little attention. Whereas pharmacological blockade of glutamate recep-

\footnotetext{
Received Feb. 1, 2013; revised March 29, 2013; accepted April 4, 2013.

Author contributions: N.S., G.I.E., and R.A.W. designed research; N.S. and B.W. performed research; N.S., G.I.E., B.W., and Z.-B.Y. analyzed data; N.S. and R.A.W. wrote the paper.

This work is supported by funding from National Institute on Drug Abuse/Intramural Research Program/National Institutes of Health/Department of Health and Human Services, N01DA59909 and DA033533. N.S. was partially supported by AA007456. We thank Stephanie Myal for her technical assistance.

Correspondence should be addressed to N. Suto, Department of Molecular and Cellular Neuroscience, The Scripps Research Institute, 10550 North Torrey Pines Road, SP30-2120, La Jolla, CA 92037. E-mail: nsuto@scripps.edu.

DOI:10.1523/JNEUROSCI.0503-13.2013

Copyright $\odot 2013$ the authors $\quad 0270-6474 / 13 / 339050-06 \$ 15.00 / 0$
}

tors in NAS core diminishes the ability of cocaine cues to promote cocaine seeking (Di Ciano and Everitt, 2001; Bäckström and Hyytiä, 2007; Xie et al., 2012), such manipulation in NAS shell reinstates and thus appears to "disinhibit" extinguished cocaine seeking (Famous et al., 2007; see also Peters et al., 2008). Blockade of glutamate receptors in the shell also appears to disinhibit food seeking being suppressed by cues predicting unavailability of food (Ambroggi et al., 2011). These findings suggest that while glutamate inputs to core signal impending reward, glutamate inputs to shell signal impending reward omission. The present study addresses this possibility.

\section{Materials and Methods}

The experimental design was based in part on previously developed operant paradigms under which each rat was trained to discriminate cues signaling cocaine availability and omission (McFarland and Ettenberg, 1997; Weiss et al., 2000; Alleweireldt et al., 2001; Di Ciano and Everitt, 2003), and consisted of three experimental phases: (1) Cocaine SelfAdministration (SA) training, (2) Discrimination Training, and (3) Discrimination Tests (Fig. 1). All procedures were approved by the local Animal Care and Use Committee. Male Long-Evans rats (Charles River), weighing 300-350 g at the time of surgery, were used. The experiments were conducted in accordance with the National Institutes of Health Guide for Care and Use of Laboratory animals and were approved by the local Institutional Animal Care and Use Committee.

First, 11 animals were used to verify the behavioral procedures. Each animal was implanted with an intravenous catheter made of MicroRenathane (Braintree Science) and housed in a dedicated operant conditioning chamber (Med Associates) throughout the entire experiments. Rats were thus trained and tested in their home environment. Each chamber was equipped with two response levers (one removable and one 


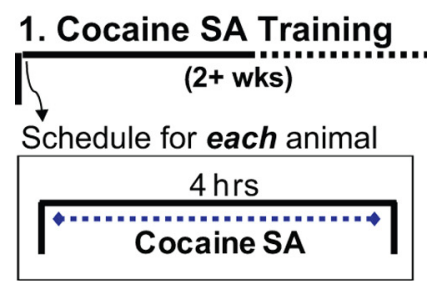

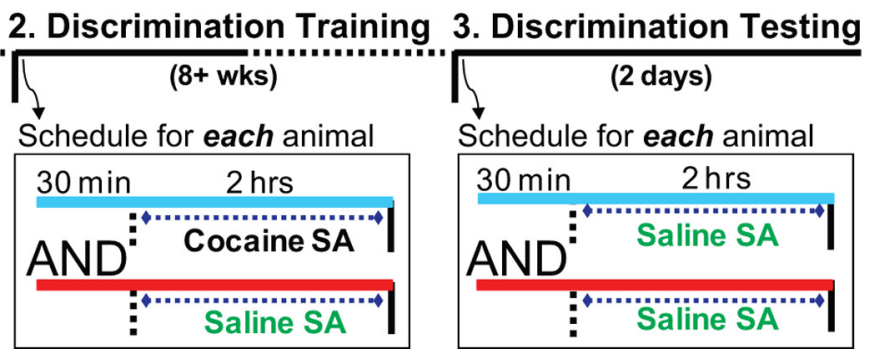

Figure 1. Time line and schedules of the behavioral procedures.

stationary), a house light, a cue light, and a liquid swivel system. At all times, insertion of the removable ("active") lever and illumination of the house light signaled the start of an SA session during which an active-lever press led to a $5 \mathrm{~s}$ intravenous injection of either cocaine $(1.0 \mathrm{mg} / \mathrm{kg} /$ injection $)$ or saline paired with $20 \mathrm{~s}$ illumination of the cue light. Pressing the stationary ("inactive") lever was recorded but had no scheduled consequence. Cocaine ([-]-cocaine hydrochloride) was obtained from the National Institute on Drug Abuse pharmacy and was dissolved in sterile saline.

During Cocaine SA Training, each rat was trained to self-administer cocaine in daily $4 \mathrm{~h}$ sessions. Each rat was required to satisfy two criteria: (1) a minimum of 2 weeks of cocaine self-administration and (2) a minimum of 30 cocaine injections for 3 consecutive days. Once these criteria were met, the animals underwent Discrimination Training where they learned that one odor cue signaled days on which cocaine would be available ("availability odor") and another odor cue signaled days on which it would not ("omission odor"). Here the sessions were shortened to $2 \mathrm{~h}$ each day and one or the other odor cue was given one-half hour before illumination of the house light and insertion of the response lever. On cocaine availability days the animals were allowed to respond (lever press), as previously trained, for intravenous cocaine. The availability odor preceded ( $30 \mathrm{~min}$ ) and accompanied the opportunity to lever press. On cocaine omission days the animals were treated identically except that the omission odor preceded ( $30 \mathrm{~min}$ ) and accompanied the opportunity to lever press and lever pressing on these days caused saline rather than cocaine delivery. The appropriate odor cue was provided by placing a Petri dish with gauze soaked with $3.0 \mathrm{ml}$ of orange or almond extract (McCormick) in the animal's chamber. Each rat was trained until responding on 3 consecutive omission days had dropped to five or fewer lever presses while earned drug intake on the intervening availability days was maintained at a minimum of 15 injections per session. Once the discrimination criteria were reached, the animals underwent Discrimination Testing. Specifically, each rat was subjected to two once daily $2 \mathrm{~h}$ sessions to self-administer saline preceded (30 $\mathrm{min}$ ) and accompanied by either availability odor or omission odor. Cocaine was not available for self-administration.

In subsequent experiments, the effects of the availability odor and the omission odor were assessed on NAS glutamate levels. Here, 40 rats were randomly assigned to four experimental groups. Two groups were implanted with an intravenous catheter and bilateral guide cannulae (CMA) aimed at the core of NAS; two groups were implanted with catheters and guide cannulae aimed at the shell (Suto et al., 2009, 2010; Suto and Wise, 2011). All rats were trained as in the initial experiment (Cocaine SA Training and Discrimination Training). Upon completion of the last training session, microdialysis probes with $1.0 \mathrm{~mm}$ active membrane (CMA Microdialysis) were bilaterally inserted, via the implanted guide cannulae, into the core (two groups) or shell (two groups) of NAS. The probes were continuously perfused with artificial CSF (aCSF) at the rate of $2.0 \mu \mathrm{l} / \mathrm{min}$. On each of the next $2 \mathrm{~d}$ the animals underwent $2 \mathrm{~h}$ sessions where lever pressing resulted in saline injections (Discrimination Testing); on one of the $2 \mathrm{~d}$ the session was preceded (30 min) and accompanied by the omission odor while on the other day it was preceded (30 min) and accompanied by the availability odor. For one group with shell cannulae and one group with core cannulae, microdialysis samples were taken at $15 \mathrm{~min}$ intervals starting $30 \mathrm{~min}$ before the odor stimulus was introduced ( $60 \mathrm{~min}$ before active-lever insertion); the samples were subsequently analyzed for their glutamate concentration (Suto

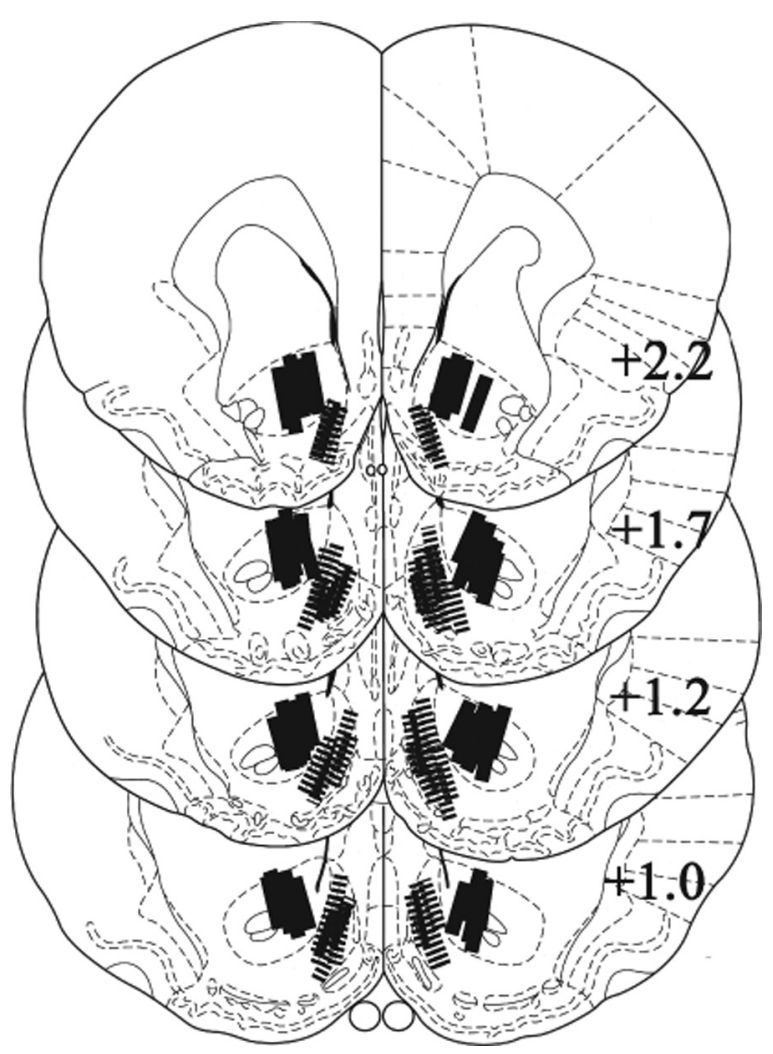

Figure 2. Localization of probe placements. Only the location of the active dialysis membrane $(1.0 \mathrm{~mm})$ is shown. Note that the probes in the shell region (hatched bars) are angled from the opposite hemisphere; this procedure avoids penetration of the ventricle and involves about the same tissue damage (Suto et al., 2009, 2010; Suto and Wise, 2011) as is seen with the core probes (solid bars), which are angled from a more lateral entry. The numbers indicate the distance (millimeters) posterior to the bregma (Paxinos and Watson, 2007).

et al., 2010). For the remaining two groups, the broad-spectrum antagonist for ionotropic glutamate receptors (iGluRs), kynurenic acid (KYN; Sigma-Aldrich), was added to the dialysate at a concentration of $1.0 \mathrm{~mm}$, starting $30 \mathrm{~min}$ before the odor stimulus was introduced and continuing throughout the testing period. This concentration of KYN, when perfused into the VTA, attenuates cocaine seeking primed by cocaine (Wise et al., 2008) or by footshock stress (Wang et al., 2009).

After completion of the experiments, the rats with cannulae were anesthetized with sodium pentobarbital and their brains removed and fixed in $10 \%$ formalin. Probe locations were identified in $40 \mu \mathrm{m}$ coronal sections stained with cresyl violet. Only data obtained from rats with both probes placed within the intended target were retained for statistical analyses (Fig. 2). As in our previous studies (Suto et al., 2009, 2010; Suto and Wise, 2011), extensive damage beyond the cannulae and probes was not noted with either the core or shell placements. Four rats were excluded from statistical analysis because one of their probes was outside the targeted area. Five rats that failed to satisfy the training criteria were excluded. Seven animals were excluded due to catheter failure or health 


\section{A Cocaine SA Training}

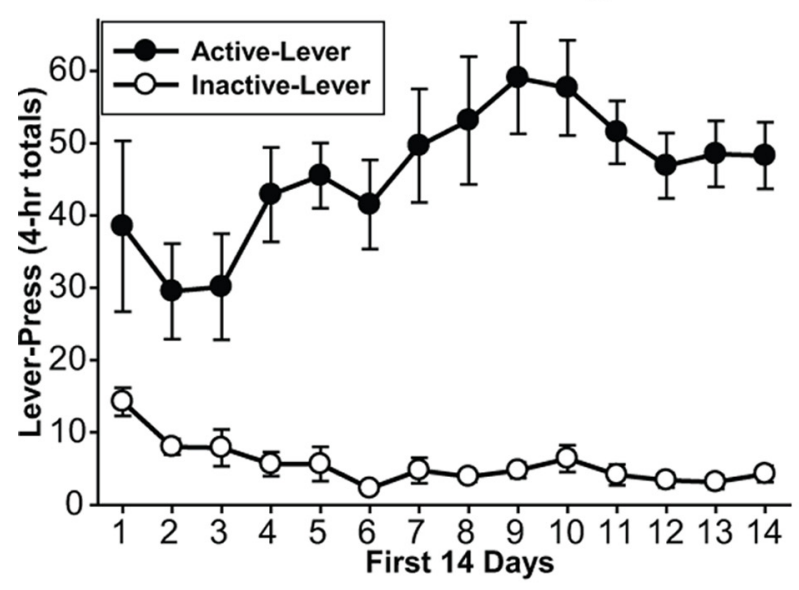

B Discrimination Training

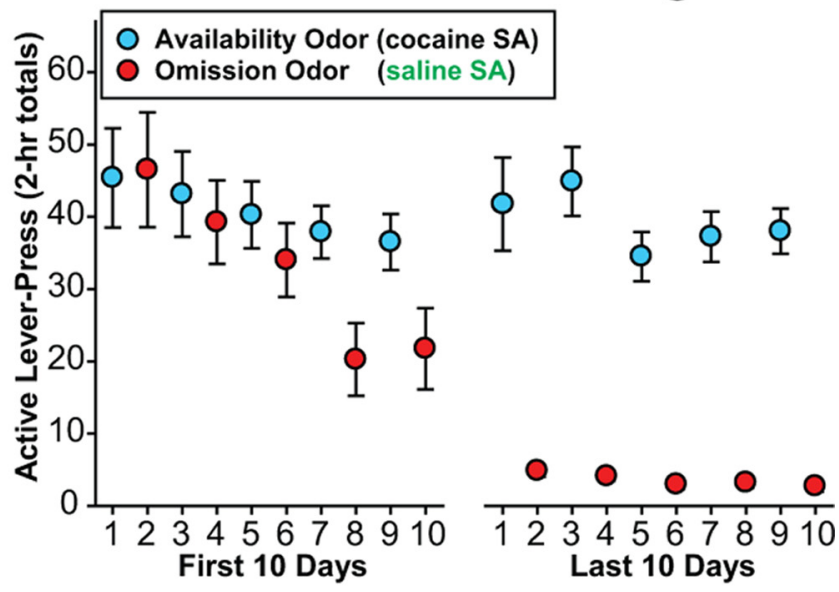

\section{Discrimination Testing}

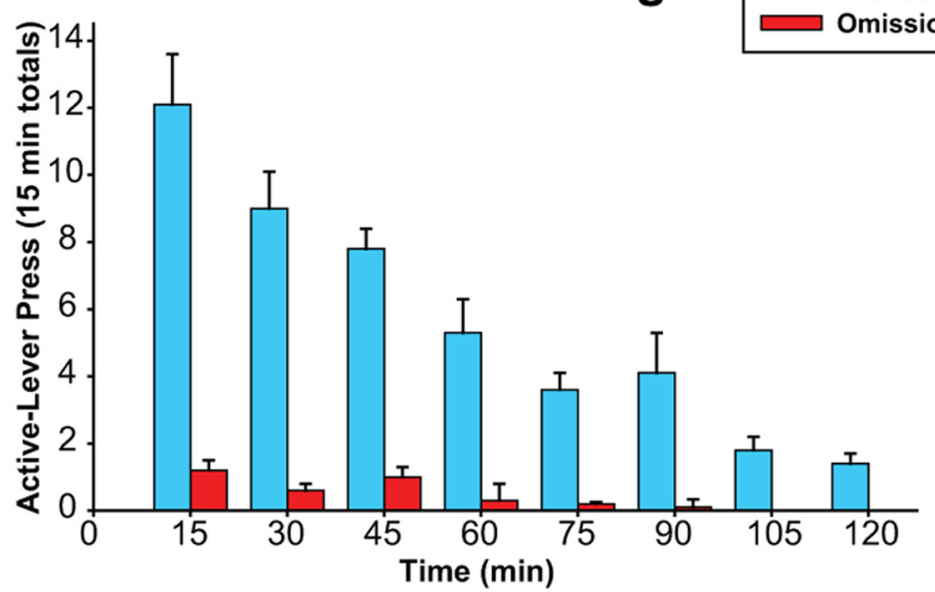

Availability Odor (saline SA)

Omission Odor (saline SA)

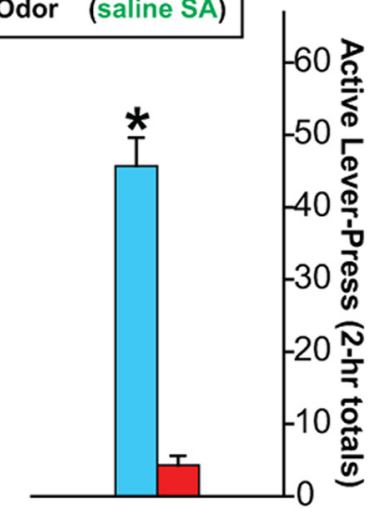

Figure 3. Lever-pressing during $(\boldsymbol{A})$ Cocaine SA Training, $(\boldsymbol{B})$ Discrimination Training, and $(\boldsymbol{C})$ Discrimination Testing (left, "time course"; right, "session total"). A0, availability odor; 00 , omission odor; SA, self-administration.

complications. Final numbers of subjects retained for the statistical analyses were as follows: $8,7,7,7$, and 6 for the first "behavioral" study, core-aCSF, shell-aCSF, core-KYN, and shell-KYN groups, respectively.

\section{Results}

During the period of Cocaine SA Training, the rats quickly learned which lever was associated with reward; their cocaine intake stabilized within a few days (Fig. 3A). A mean of 18.1 training sessions (SEM \pm 0.8 ) was required before the training criteria were satisfied. The mean numbers $( \pm$ SEM) of cocaine self-injections, active-lever presses, and inactive-lever presses made during the final training session were $49.5( \pm 2.7), 60.5$ $( \pm 4.1)$, and $2.9( \pm 4.1)$, respectively. During Discrimination Training, the rats maintained a stable level of active-lever pressing on cocaine availability days, but progressively decreased responding on cocaine omission days (Fig. 3B). A mean of 21.1 omission sessions ( $\mathrm{SEM} \pm 2.1$ ) were required before the training criteria were satisfied. During the initial period of this phase, the rates of cocaine intake were somewhat higher than those during the final period of Cocaine SA Training. Introduction of a novel stimulus, namely the odor cue, may account for such increase in responding. During Discrimination Testing (Fig. 3C), the responding was significantly different between the two odor conditions $\left(t_{(7)}=8.18, p<0.001\right)$. Presentation of the availability odor triggered vigorous lever pressing despite the fact that, unlike during the previous Discrimination Training, it no longer resulted in cocaine injection. In contrast, the rats lever pressed minimally under an otherwise identical condition, when the omission odor was present.

Glutamate levels in the core and shell were each elevated in response to the availability odor and were depressed in the core and shell in response to the omission odor. These effects were evident in samples collected before each saline selfadministration test (Fig. $4 A$ ), thus preceded the initiation of cocaine seeking (Treatment $\left[\left(F_{(1,1)}=8.56, p<0.05\right]\right.$, Odor $\times$ Treatment $\left[F_{(1,12)}=48.15, p<0.001\right]$, Odor $\times$ Treatment $\times$ Site $\left.\left[F_{(1,12)}=4.39, p=0.057\right]\right)$. When the availability odor was present, glutamate remained significantly elevated ( $p s<0.01-0.05$ ) in core (Time $\left[F_{(10,60)}=3.88, p<0.001\right]$ ) and shell (Time $\left.\left[F_{(10,60)}=7.09, p<0.001\right]\right)$ through most of the $2 \mathrm{~h}$ saline $\mathrm{SA}$ test (Fig. $4 B$ ). When the omission odor was present, glutamate remained depressed $(p s<0.05)$ in core (Time $\left[F_{(10,60)}=3.45, p<\right.$ $0.001])$. However, similar depression in shell was not statistically reliable (Time $\left.\left[F_{(10,60)}=0.94, \mathrm{NS}\right]\right)$.

Pharmacological blockade of iGluRs in core but not shell decreased the promotion of cocaine seeking associated with the availability odor, while such manipulation in neither core nor 

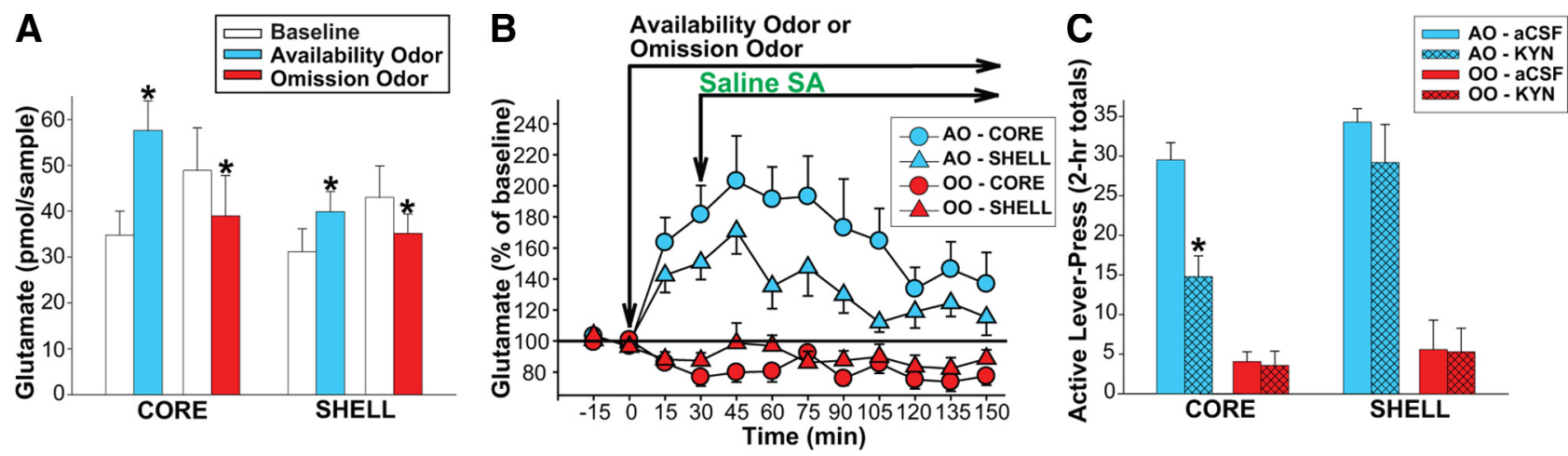

Figure 4. Discrimination Testing with microdialysis. Note that the animals tested with the availability odor (A0) expected cocaine in the presence of that odor whereas the animals tested with the omission odor (00) did not. $A$, Extracellular glutamate in core and shell during the time period preceding the initiation of cocaine seeking (saline SA). White bars represent the average concentrations ( + SEM) in baseline samples. Colored bars represent the average concentrations ( + SEM) in samples collected at the two time points immediately following the introduction of A0 or $00 .{ }^{*} p<0.01-0.001$, compared with the baseline levels. $B$, Time course of extracellular glutamate fluctuations in core and shell. $\boldsymbol{C}$, Effects of KYN perfusion into core or shell on cocaine-seeking response (saline $S A) .{ }^{*} p<0.01$, compared with $\mathrm{A} 0$-aCSF.

shell altered the suppression associated with the omission odor (Fig. 4C). This was reflected in significant effects of Odor $\left.\left(F_{(1,23}\right)=147.59, p<0.001\right)$, Perfusion $\left(F_{(1,23)}=14.39, p<\right.$ $0.01)$, and Site $\left(F_{(1,23)}=16.46, p<0.001\right)$ as well as Odor $\times$ Site $(=6.31, p<0.05)$ and Odor $\times$ Perfusion $\left(F_{(1,23)}=8.65, p<\right.$ $0.01)$ interactions.

\section{Discussion}

The primary finding in the present study was that responseindependent presentation of the cocaine omission cue depressed glutamate in the core and shell of NAS. This cue-evoked depression preceded the opportunity to lever press, and is thus a response to the omission cue rather than a response to the failure of the operant response to deliver cocaine. When given the opportunity to respond, the rats lever pressed minimally, while glutamate remained depressed in the core. Cue-evoked depression of NAS glutamate is a novel finding that raises interesting questions about the mechanisms of drug cravings. Drug craving can fail to develop in the presence of discriminative stimuli associated with drug unavailability. For example, flight attendants have absent or reduced cravings for cigarettes in the context of a long flight where they know they cannot smoke (Dar et al., 2010) and orthodox Jews have absent or reduced cravings for cigarettes in the context of their Sabbath, when they do not smoke (Dar et al., 2005). Similarly, American servicemen who were addicted to heroin in Viet Nam reported absent or reduced cravings for heroin when returning to the context of their homes in the United States (Robins et al., 1974). The present data suggest that decreased glutamate inputs to NAS mediate cued suppression of drug craving. Consistent with this presumption, cognitive suppression of cue-triggered craving in cocaine addicts is associated with depressed metabolic activity in NAS (Volkow et al., 2010).

A complimentary finding was that response-independent presentation of the availability cue was sufficient to elevate extracellular glutamate in two subregions of NAS, core and shell-a finding that extends a previous report (Hotsenpiller et al., 2001). This cue-evoked elevation preceded the opportunity to lever press, and is thus a response to the availability cue rather than to the act or the outcomes of cocaine seeking. When the opportunity was given, rats actively engaged in lever pressing that resulted in conditioned reinforcing stimuli only, and glutamate remained elevated in core and shell. These findings complement previous findings that response-dependent presentations of conditioned reinforcers during cocaine extinction (Suto et al., 2010) as well as heroin reinstatement (LaLumiere and Kalivas, 2008) elevate extracellular glutamate in NAS. Blockade of iGluRs in core but not shell attenuated the promotion of cocaine seeking triggered by the availability cue. Together with previous reports (Di Ciano and Everitt, 2001; Bäckström and Hyytiä, 2007; Di Ciano et al., 2008; Xie et al., 2012), the present data support the hypothesis that glutamate inputs to NAS core-along with glutamate inputs to other brain regions, such as VTA (Wise, 2009) — carry information regarding impending cocaine availability, and therefore is a potential source of cue-induced cocaine craving and relapse (Kalivas, 2009).

In the current study, pharmacological blockade of iGluRs in neither core nor shell altered the suppression of cocaine seeking associated with the omission cue. On the contrary, blockade of iGluRs in the shell is previously-though not universally (Xie et al., 2012)—reported to "disinhibit" extinguished cocaine seeking (Famous et al., 2007) and omission cue-suppressed food seeking (Ambroggi et al., 2011). In addition, a microinjection of $\gamma$-aminobutyric acid agonists into the shell-an experimental manipulation to inhibit local neurons in a manner similar to a microinjection of glutamate antagonists-also appears to disinhibit extinguished cocaineseeking (Peters et al., 2008). The long (60 min) pre-response period of KYN perfusion in the current study may have dissipated such disinhibition. It is, however, critical to note that stimulation of iGluRs in the shell also disinhibits extinguished cocaine seeking (Ping et al., 2008; see also Cornish et al., 1999; Cornish and Kalivas, 2000; Suto et al., 2004). Furthermore, blockade of iGluRs in the shell increases spontaneous locomotion (Pulvirenti et al., 1994) and feeding (Maldonado-Irizarry et al., 1995). In short, the behavioral effects of glutamate blockade in shell are complex, and appear not necessarily specific to disinhibiting reward seeking. Nonselective procedures to manipulate glutamatergic neurotransmission (reverse dialysis in the current study and microinjection in the previous studies) may have also contributed to the contradictory findings regarding the role of the shell in cue-modulation of cocaine seeking.

The neurocircuitry mediating the bidirectional cue modulation of glutamate inputs to NAS remains to be determined. Multiple glutamate afferents-including innervations from various subregions of prefrontal cortex, hippocampus, amygdala, and thalamus-converge in NAS (Sesack and Grace, 2010) and each 
has been suggested to contribute to reward (Britt et al., 2012). In particular, the projection from the prelimbic cortex, a subregion of the medial prefrontal cortex, to NAS core is implicated in relapse promotion by drug-availability cues (Kalivas and Volkow, 2005), and thus could be the neuroanatomical origin of cueevoked glutamate elevation in NAS. Glutamatergic input to NAS also arises from the medial thalamus (Christie et al., 1987), an input that has received limited attention in addiction models (Young and Deutch, 1998). A glutamatergic projection from the VTA has also recently been characterized (Yamaguchi et al., 2011), and the ventral tegmental area is known to receive cocaine-predictive glutamatergic (You et al., 2007) and cholinergic (You et al., 2008) input. Nonsynaptic sources via cysteineglutamate exchanger (Baker et al., 2003) may also contribute to the bidirectional cue modulation of NAS glutamate and cocaine seeking. Thus the roles in addiction and reward of glutamatergic input to NAS are likely to be even more complex than those suggested by the present experiments.

\section{References}

Alleweireldt AT, Weber SM, Neisewander JL (2001) Passive exposure to a contextual discriminative stimulus reinstates cocaine-seeking behavior in rats. Pharmacol Biochem Behav 69:555-560. CrossRef Medline

Ambroggi F, Ghazizadeh A, Nicola SM, Fields HL (2011) Roles of nucleus accumbens core and shell in incentive-cue responding and behavioral inhibition. J Neurosci 31:6820-6830. CrossRef Medline

Bäckström P, Hyytiä P (2007) Involvement of AMPA/kainate, NMDA, and mGlu5 receptors in the nucleus accumbens core in cue-induced reinstatement of cocaine seeking in rats. Psychopharmacology 192:571-580. CrossRef Medline

Baker DA, McFarland K, Lake RW, Shen H, Tang XC, Toda S, Kalivas PW (2003) Neuroadaptations in cystine-glutamate exchange underlie cocaine relapse. Nat Neurosci 6:743-749. CrossRef Medline

Britt JP, Benaliouad F, McDevitt RA, Stuber GD, Wise RA, Bonci A (2012) Synaptic and behavioral profile of multiple glutamatergic inputs to the nucleus accumbens. Neuron 76:790-803. CrossRef Medline

Childress A, Ehrman R, McLellan AT, O’Brien C (1988) Conditioned craving and arousal in cocaine addiction: a preliminary report. NIDA Res Monogr 81:74-80. Medline

Christie MJ, Summers RJ, Stephenson JA, Cook CJ, Beart PM (1987) Excitatory amino acid projections to the nucleus accumbens septi in the rat: a retrograde transport study utilizing $\mathrm{D}[3 \mathrm{H}]$ aspartate and $[3 \mathrm{H}] \mathrm{GABA}$. Neuroscience 22:425-439. CrossRef Medline

Cornish JL, Kalivas PW (2000) Glutamate transmission in the nucleus accumbens mediates relapse in cocaine addiction. J Neurosci 20:RC89. Medline

Cornish JL, Duffy P, Kalivas PW (1999) A role for nucleus accumbens glutamate transmission in the relapse to cocaine-seeking behavior. Neuroscience 93:1359-1367. CrossRef Medline

Dar R, Stronguin F, Marouani R, Krupsky M, Frenk H (2005) Craving to smoke in orthodox Jewish smokers who abstain on the Sabbath: a comparison to a baseline and a forced abstinence workday. Psychopharmacology 183:294-299. CrossRef Medline

Dar R, Rosen-Korakin N, Shapira O, Gottlieb Y, Frenk H (2010) The craving to smoke in flight attendants: relations with smoking deprivation, anticipation of smoking, and actual smoking. J Abnorm Psychol 119:248-253. CrossRef Medline

Di Ciano P, Everitt BJ (2001) Dissociable effects of antagonism of NMDA and AMPA/KA receptors in the nucleus accumbens core and shell on cocaine-seeking behavior. Neuropsychopharmacology 25:341-360. CrossRef Medline

Di Ciano P, Everitt BJ (2003) Differential control over drug-seeking behavior by drug-associated conditioned reinforcers and discriminative stimuli predictive of drug availability. Behav Neurosci 117:952-960. CrossRef Medline

Di Ciano P, Robbins TW, Everitt BJ (2008) Differential effects of nucleus accumbens core, shell, or dorsal striatal inactivations on the persistence, reacquisition, or reinstatement of responding for a drug-paired conditioned reinforcer. Neuropsychopharmacology 33:1413-1425. CrossRef Medline
Ehrman RN, Robbins SJ, Childress AR, O'Brien CP (1992) Conditioned responses to cocaine-related stimuli in cocaine abuse patients. Psychopharmacology 107:523-529. CrossRef Medline

Famous KR, Schmidt HD, Pierce RC (2007) When administered into the nucleus accumbens core or shell, the NMDA receptor antagonist AP-5 reinstates cocaine-seeking behavior in the rat. Neurosci Lett 420:169 173. CrossRef Medline

Hotsenpiller G, Giorgetti M, Wolf ME (2001) Alterations in behaviour and glutamate transmission following presentation of stimuli previously associated with cocaine exposure. Eur J Neurosci 14:1843-1855. CrossRef Medline

Kalivas PW (2009) The glutamate homeostasis hypothesis of addiction. Nat Rev Neurosci 10:561-572. CrossRef Medline

Kalivas PW, Volkow ND (2005) The neural basis of addiction: a pathology of motivation and choice. Am J Psychiatry 162:1403-1413. CrossRef Medline

Kosten TR, Scanley BE, Tucker KA, Oliveto A, Prince C, Sinha R, Potenza MN, Skudlarski P, Wexler BE (2006) Cue-induced brain activity changes and relapse in cocaine-dependent patients. Neuropsychopharmacology 31:644-650. CrossRef Medline

LaLumiere RT, Kalivas PW (2008) Glutamate release in the nucleus accumbens core is necessary for heroin seeking. J Neurosci 28:3170-3177. CrossRef Medline

Maldonado-Irizarry CS, Swanson CJ, Kelley AE (1995) Glutamate receptors in the nucleus accumbens shell control feeding behavior via the lateral hypothalamus. J Neurosci 15:6779-6788. Medline

McFarland K, Ettenberg A (1997) Reinstatement of drug-seeking behavior produced by heroin-predictive environmental stimuli. Psychopharmacology 131:86-92. CrossRef Medline

Meil WM, See RE (1996) Conditioned cued recovery of responding following prolonged withdrawal from self-administered cocaine in rats: an animal model of relapse. Behav Pharmacol 7:754-763. Medline

Paxinos G, Watson C (2007) The rat brain in stereotaxic coordinates, Ed 6. Boston: Academic/Elsevier.

Peters J, LaLumiere RT, Kalivas PW (2008) Infralimbic prefrontal cortex is responsible for inhibiting cocaine seeking in extinguished rats. J Neurosci 28:6046-6053. CrossRef Medline

Ping A, Xi J, Prasad BM, Wang MH, Kruzich PJ (2008) Contributions of nucleus accumbens core and shell GluR1 containing AMPA receptors in AMPA- and cocaine-primed reinstatement of cocaine-seeking behavior. Brain Res 1215:173-182. CrossRef Medline

Pulvirenti L, Berrier R, Kreifeldt M, Koob GF (1994) Modulation of locomotor activity by NMDA receptors in the nucleus accumbens core and shell regions of the rat. Brain Res 664:231-236. CrossRef Medline

Robins LN, Davis DH, Goodwin DW (1974) Drug use by U.S. Army enlisted men in Vietnam: a follow-up on their return home. Am J Epidemiol 99:235249. Medline

Sesack SR, Grace AA (2010) Cortico-basal ganglia reward network: microcircuitry. Neuropsychopharmacology 35:27-47. CrossRef Medline

Suto N, Wise RA (2011) Satiating effects of cocaine are controlled by dopamine actions in the nucleus accumbens core. J Neurosci 31: 17917-17922. CrossRef Medline

Suto N, Tanabe LM, Austin JD, Creekmore E, Pham CT, Vezina P (2004) Previous exposure to psychostimulants enhances the reinstatement of cocaine seeking by nucleus accumbens AMPA. Neuropsychopharmacology 29:2149-2159. CrossRef Medline

Suto N, Ecke LE, Wise RA (2009) Control of within-binge cocaine-seeking by dopamine and glutamate in the core of nucleus accumbens. Psychopharmacology 205:431-439. CrossRef Medline

Suto N, Ecke LE, You ZB, Wise RA (2010) Extracellular fluctuations of dopamine and glutamate in the nucleus accumbens core and shell associated with lever-pressing during cocaine self-administration, extinction, and yoked cocaine administration. Psychopharmacology 211:267-275. CrossRef Medline

Volkow ND, Fowler JS, Wang GJ, Telang F, Logan J, Jayne M, Ma Y, Pradhan K, Wong C, Swanson JM (2010) Cognitive control of drug craving inhibits brain reward regions in cocaine abusers. Neuroimage 49:2536-2543. CrossRef Medline

Wang B, Shaham Y, Zitzman D, Azari S, Wise RA, You ZB (2005) Cocaine experience establishes control of midbrain glutamate and dopamine by corticotropin-releasing factor: a role in stress-induced relapse to drug seeking. J Neurosci 25:5389-5396. CrossRef Medline 
Wang B, You ZB, Wise RA (2009) Reinstatement of cocaine seeking by hypocretin (orexin) in the ventral tegmental area: independence from the local corticotropin-releasing factor network. Biol Psychiatry 65: 857-862. CrossRef Medline

Wang B, You ZB, Wise RA (2012) Heroin self-administration experience establishes control of ventral tegmental glutamate release by stress and environmental stimuli. Neuropsychopharmacology 37:2863-2869. CrossRef Medline

Weiss F, Maldonado-Vlaar CS, Parsons LH, Kerr TM, Smith DL, Ben-Shahar O (2000) Control of cocaine-seeking behavior by drug-associated stimuli in rats: effects on recovery of extinguished operant-responding and extracellular dopamine levels in amygdala and nucleus accumbens. Proc Natl Acad Sci U S A 97:4321-4326. CrossRef Medline

Wise RA (2009) Ventral tegmental glutamate: a role in stress-, cue-, and cocaine-induced reinstatement of cocaine-seeking. Neuropharmacology 56 [Suppl 1]:174-176. CrossRef Medline

Wise RA, Wang B, You ZB (2008) Cocaine serves as a peripheral interoceptive conditioned stimulus for central glutamate and dopamine release. PLoS One 3:e2846. CrossRef Medline
Xie X, Lasseter HC, Ramirez DR, Ponds KL, Wells AM, Fuchs RA (2012) Subregion-specific role of glutamate receptors in the nucleus accumbens on drug context-induced reinstatement of cocaine-seeking behavior in rats. Addict Biol 17:287-299. CrossRef Medline

Yamaguchi T, Wang HL, Li X, Ng TH, Morales M (2011) Mesocorticolimbic glutamatergic pathway. J Neurosci 31:8476-8490. CrossRef Medline

You ZB, Wang B, Zitzman D, Azari S, Wise RA (2007) A role for conditioned ventral tegmental glutamate release in cocaine seeking. J Neurosci 27:10546-10555. CrossRef Medline

You ZB, Wang B, Zitzman D, Wise RA (2008) Acetylcholine release in the mesocorticolimbic dopamine system during cocaine seeking: conditioned and unconditioned contributions to reward and motivation. J Neurosci 28:9021-9029. CrossRef Medline

Young CD, Deutch AY (1998) The effects of thalamic paraventricular nucleus lesions on cocaine-induced locomotor activity and sensitization. Pharmacol Biochem Behav 60:753-758. CrossRef Medline 